Pacific Journal of Mathematics

BASES IN HILBERT SPACE

BadMonth 1968 


\title{
BASES IN HILBERT SPACE
}

\author{
WILLIAM J. DAVIS
}

\begin{abstract}
A sequence $\left(x_{i}\right)$ of elements of a Hilbert space, $\mathscr{C}$, is a basis for $\mathscr{H}$ if every $h \in \mathscr{H}$ has a unique, norm-convergent expansion of the form $h=\sum a_{i} x_{i}$, where $\left(a_{i}\right)$ is a sequence of scalars. The sequence is minimal if there exists a sequence $\left(y_{i}\right) \subset \mathscr{H}$ such that $\left(x_{i}, y_{j}\right)=\delta_{i j}$. Every basis is minimal, and the sequence $\left(a_{i}\right)$ in the expansion of $h$ (above) is given by $a_{i}=\left(h, y_{i}\right)$. In this paper, we restrict our attention to real Hilbert space.

We derive, from classical characterizations of bases in $B$ spaces, criterea for $\left(x_{i}\right)$ to be a basis for $\mathscr{H}$, as well as for $\left(x_{i}\right)$ to be minimal in $\mathscr{H}$. We show that the sequence is minimal if and only if there are sequences $\left(g_{i}\right) \subset \mathscr{C}$ whose Gram matrices have a prescribed form. Similar conditions are obtained for $\left(x_{i}\right)$ to be a basis for $\mathscr{H}$.
\end{abstract}

Let $\left(x_{i}\right)$ be a linearly independent sequence of elements of $\mathscr{K}$. Using the Gram-Schmidt process, one finds an orthonormal basis, $\left(w_{i}\right)$, for the closed span, $\left[x_{i}\right]$ of the sequence $\left(x_{i}\right)$. We assume throughout that $\left[x_{i}\right]=\mathscr{H}_{\text {. }}$ Then, we may write

$$
x_{i}=\sum_{j=0}^{i} p_{i j} w_{j}
$$

and

$$
w_{i}=\sum_{j=0}^{i} q_{i j} x_{j}
$$

If we let $P$ and $Q$ denote the matrices $\left(p_{i j}\right)$ and $\left(q_{i j}\right)$, respectively, then each is lower triangular, and $P Q=Q P=I=\left(\delta_{i j}\right)$. It is a classical result that $Q$ is the unique inverse of $P$.

For $\left(x_{i}\right)$ to be minimal, we need a sequence $\left(y_{i}\right)$ such that $\left(x_{i}, y_{j}\right)=$ $\delta_{i j}$. It is easy to see that, formally, $y_{i}=\sum_{y=i}^{\infty} q_{j i} w_{j}$. Further, the sequence is minimal if and only if the distance from $x_{k}$ to $\left[x_{j}\right], j \neq k$ is positive. Using these facts, we get the following theorem. The second part is similar to the characterization of minimality due to Foias and Singer [2].

THEOREM 1. Let $H=\left(h_{i j}\right)$ denote the Gram matrix of $\left(x_{i}\right)$, i.e., $h_{i j}=\left(x_{i}, x_{j}\right)$. Then the sequence is minimal if and only if any of the following conditions holds:

(a) The matrix $R=Q^{T} Q$ exists.

(b) There exists a sequence, $\left(\delta_{i}\right)$, with $\delta_{i}>0$ for all $i$, such 
that for all real vectors $A=\left(a_{0}, a_{1}, \cdots, a_{n}, 0, \cdots\right), A H A^{T} \geqq \sum \delta_{i} a_{i}^{2}$. (c) There exists a sequence $\left(\varepsilon_{i}\right)$ with $\varepsilon_{i}>0$ for all $i$ such that $A R A^{T} \geqq \sum \varepsilon_{i} a_{i}^{2}$, with $A$ as in (b).

Proof. (a) Follows from the formal relation $y_{i}=\sum q_{j i} w_{j}$. For (b), notice that $A H A^{T} \geqq\left\|\sum a_{i} x_{i}\right\|^{2}$. If $\left(x_{i}\right)$ is minimal, then $A H A^{T} \geqq$ $\lambda_{i}\left\|x_{i}\right\|^{2} a_{i}^{2}$, where $\lambda_{i}^{1 / 2}$ is the distance from $x_{i} /\left\|x_{i}\right\|$ to $\left[x_{j}\right], j \neq i$. Therefore, for each permutation $\left(n_{i}\right)$ of the nonnegative integers,

$$
A H A^{T} \geqq \sum a^{-\left(n_{i}+1\right)} \lambda_{i} a_{i}^{2}\left\|x_{i}\right\|^{2} .
$$

So $\delta_{i}=2^{-\left(n_{i}+1\right)} \lambda_{i}\left\|x_{i}\right\|^{2}$ works. On the other hand, if $A H A^{T} \geqq \sum \delta_{i} a_{i}^{2}$, then $A H A^{T} \geqq \delta_{i} a_{i}^{2}=\lambda_{i}\left\|x_{i}\right\|^{2} a_{i}^{2}$ for each $i$. Part (c) follows since $\left(y_{i}\right)$ is minimal if and only if $\left(x_{i}\right)$ is minimal.

2. Here we derive further criteria, for minimal and basic sequences, which depend upon the existence of certain Gram matrices. First, we recall that a fundamental sequence $\left(x_{i}\right)$ in a $B$-space is minimal if and only if, for each $n$, there exists a constant $K_{n} \geqq 1$ such that, for all $m$ and all sequences $\left(a_{j}\right)$,

$$
\left\|\sum_{j=0}^{n} a_{j} x_{j}\right\| \leqq K_{N}\left\|\sum_{j=0}^{n+m} a_{j} x_{j}\right\| \text {. }
$$

Further, such a sequence is basic if and only if $\left(K_{n}\right)$ is bounded (that is, if and only if a bounded sequence $\left(K_{n}\right)$ can be chosen) [1]. In either case, $K_{n}$ is to be chosen in such a way that

$$
\left\{K_{n}^{2}\left\|\sum_{j=0}^{n+m} a_{j} x_{j}\right\|^{2}-\left\|\sum_{j=0}^{n} a_{j} x_{j}\right\|^{2}\right\}
$$

defines a positive definite form on the collection of all finite real sequences. Associated with this form is the matrix $S=S\left(n, K_{n}\right)$, defined as follows:

$$
S_{i j}=\left\{\begin{array}{l}
\left(K_{n}^{2}-1\right)\left(x_{i}, x_{j}\right) ; 1 \leqq i, j \leqq n \\
K_{n}^{2}\left(x_{i}, x_{j}\right) ; \text { otherwise }
\end{array}\right.
$$

The positive definiteness of the form $A S A^{T}$ will be achieved over the finite vectors $A=\left(a_{1}, a_{2}, \cdots, a_{n}, 0, \cdots\right)$ if and only if each principal $k \times k$ submatrix, $S^{(k)}$ of $S$ is positive definite. Each $S^{(k)}$ is positive definite if and only if there exists a real, nonsingular, lower triangular matrix $T$ such that $S^{(k)}=T^{(k)} T^{(k)^{T}}$. A routine calculation shows that

$$
T_{i j}=\left\{\begin{array}{l}
\sqrt{K_{n}^{2}-1} p_{i j} ; 1 \leqq i, j \leqq n \\
\frac{K_{n}^{2}}{\sqrt{K_{n}^{2}-1}} p_{i j} ; i>n, 1 \leqq j \leqq n .
\end{array}\right.
$$


Thus, we must solve, in the reals, the equations

$$
\begin{aligned}
\sum_{j=n+1}^{i} T_{i j} T_{k j}= & K_{n}^{2}\left(x_{i}, x_{k}\right) \\
& -\frac{K_{n}^{4}}{K_{n}^{2}-1}\left(\pi_{n} x_{i}, x_{k}\right),
\end{aligned}
$$

where $\pi_{n} x_{i}=\sum_{j=1}^{n} p_{i j} w_{j}$. If these equations are solvable, then $S$ is positive definite (over finite $A$ ), if and only if $T_{i i} \neq 0$. Now let $\left(f_{i}\right)_{i=n+1}^{\infty}$ be any linearly independent sequence in $\mathscr{C}$ for which

$$
\left(f_{i}, f_{j}\right)=K_{n}^{2}\left(x_{i}, x_{j}\right)-\left(\frac{K_{n}^{4}}{K_{n}^{2}-1}\right)\left(\pi_{n} x_{i}, x_{j}\right),
$$

if it exists. If we orthonormalize $\left(f_{i}\right)$, we get a sequence $\left(g_{i}\right)_{i=n+1}^{\infty}$ and

$$
f_{i}=\sum_{j=n+1}^{i} T_{i j} g_{j}
$$

Linear independence of $\left(f_{i}\right)$ gives $T_{i i} \neq 0$. On the other hand, if the equations above are solvable, for $\left(T_{i j}\right)$, we may set $f_{i}=\sum_{j=n+1}^{i} T_{i j} w_{j}$. We have the following theorem:

THEOREM 2. The sequence $\left(x_{i}\right)$ is

(a) minimal if and only if, for each $n$, there exists $K_{n} \geqq 1$ and a linearly independent sequence $\left(f_{i}\right)_{i=n+1}^{\infty}$ such that

$$
\left(f_{i}, f_{j}\right)=K_{n}^{2}\left(x_{i}, x_{j}\right)-\frac{K_{n}^{4}}{K_{n}^{2}-1}\left(\pi_{n} x_{i}, x_{j}\right) .
$$

(b) a basis if and only if it is minimal, and the sequence $\left(K_{n}\right)$ may be chosen so that it is bounded.

The sequence $\left(x_{j}\right)$ is minimal if and only if, for each $n$. there exists $C_{n} \geqq 1$ such that, for all $m$ and sequences $\left(a_{i}\right)$,

$$
\left\|\sum_{i=n+1}^{n+m} a_{i} x_{i}\right\| \leqq C_{n}\left\|\sum_{i=1}^{n+m} a_{i} x_{i}\right\| \text {. }
$$

It is basic if and only if $\left(C_{n}\right)$ may be chosen as a bounded sequence (see, e.g., [4]). Using these facts, and arguments similar to those for Theorem 2, we obtain,

Theorem 3. The sequence $\left(x_{i}\right)$ is

(a) minimal if and only if, for each $n$, there exists $C_{n} \geqq 1$ and a linearly independent sequence $\left(g_{i}\right)_{i=n+1}^{\infty}$ such that, for $i, j>n$, 


$$
\left(g_{i}, g_{j}\right)=\left(C_{n}^{2}-1\right)\left(x_{i}, x_{j}\right)-C_{n}^{2}\left(\pi_{n} x_{i}, x_{j}\right)
$$

and

(b) basic if and only if it is minimal and $\left(C_{n}\right)$ may be chosen as a bounded sequence.

In deriving Theorem 3, one must determine the positive definiteness of the matrices $S$ defined by

$$
S_{i j}=\left\{\begin{array}{l}
C_{n}^{2}\left(x_{i}, x_{j}\right) ; 1 \leqq i \leqq n \text { or } 1 \leqq j \leqq n \\
\left(C_{n}^{2}-1\right)\left(x_{i}, x_{j}\right) ; i, j>n
\end{array}\right.
$$

An interesting characterization of minimal sequences and bases is the following.

Proposition. The sequence $\left(x_{i}\right)$ is

(a) minimal if its Gram matrix, $H$, is strictly diagonally dominant, and

(b) a basis if its Gram matrix is uniformly diagonally dominant. ${ }^{1}$

Proof. If $H$ is strictly diagonally dominant, for each $n$ there exists $\gamma_{n} \in(0,1)$ such that $\gamma_{n}\left|\left(x_{n}, x_{n}\right)\right|<\sum_{j \neq n}\left|\left(x_{n}, x_{j}\right)\right|$. Then, for $C_{n}^{2}=1 / \gamma_{n}$, the matrix $S$ is strictly diagonally dominant, and hence positive definite over finite $A[5]$. Part (b) follows in the same manner.

Using the same method of proof, Theorems 3 and 4 , and the fact that the positive definite $n \times n$ matrices define a cone in the linear space of all $n \times n$ matrices, we obtain the most general form of our characterization of minimal sequences and bases in $\mathscr{H}$.

THEOREM 4. The sequence $\left(x_{i}\right)$ is

(a) minimal if and only if, some (and hence all) $\alpha, \beta>0$ and all $n$, there exist $K_{n}, C_{n} \geqq 1$ and $\left(g_{i}\right)_{i=n+1}^{\infty}$ such that, for $i, j>n$,

$$
\begin{aligned}
\left(g_{i}, g_{j}\right)= & \left(\alpha K_{n}^{2}+\beta C_{n}^{2}-\beta\right)\left(x_{i}, x_{j}\right) \\
& -\left(\frac{\left(\alpha K_{n}^{2}+B C_{n}^{2}\right)^{2}}{\alpha K_{n}^{2}+\beta C_{n}^{2}-\alpha}\right)\left(\pi_{n} x_{i}, x_{j}\right),
\end{aligned}
$$

and

A symmetric matrix $A$ is strictly diagonally dominant [5] if $\left|a_{i i}\right|>\sum_{j \neq i}\left|a_{i j}\right|$ for all $i$, and is uniformly diagonally dominant if there exists $\gamma \in(0,1)$ such that $\gamma\left|a_{i i}\right| \geqq$ $\sum_{j \neq i}\left|a_{i j}\right|$ for each $i$. 
(b) a basis if and only if $\left(K_{n}\right)$ and $\left(C_{n}\right)$ may be chosen as bounded sequences.

\section{REFERENCES}

1. S. Banach, Theorie des operationes lineaires, Warsaw, 1932.

2. C. Foias and I. Singer, Some remarks on strongly linearly independent sequences and bases inBanach spaces, Revue de math pures et appl. 6 (1961), 589-594.

3. B. Kacymarz and H. Steinhaus, Theorie der orthogonalreihen, Warsaw, 1935.

4. I. Singer, Baze in spatie Banach, I, Studii si Cercetari Matematice, R. P. R. 14 (1963), 533-585.

5. R. Varga, Matrix iterative analysis, Princeton, N. J., 1962.

Received December 13, 1966. This work was supported by National Science Foundation Grant number GP-6152.

The OHio State University 



\section{PACIFIC JOURNAL OF MATHEMATICS}

\section{EDITORS}

\section{H. ROYDEN}

Stanford University

Stanford, California

R. R. Phelps

University of Washington

Seattle, Washington 98105

\section{J. DugundJI}

Department of Mathematics

University of Southern California

Los Angeles, California 90007

RICHARD ARENS

University of California

Los Angeles, California 90024

\section{ASSOCIATE EDITORS}
E. F. BeCKENBACH
B. H. NeumanN
F. WOLF
K. YosIDA

\section{SUPPORTING INSTITUTIONS}

\author{
UNIVERSITY OF BRITISH COLUMBIA \\ CALIFORNIA INSTITUTE OF TECHNOLOGY \\ UNIVERSITY OF CALIFORNIA \\ MONTANA STATE UNIVERSITY \\ UNIVERSITY OF NEVADA \\ NEW MEXICO STATE UNIVERSITY \\ OREGON STATE UNIVERSITY \\ UNIVERSITY OF OREGON \\ OSAKA UNIVERSITY \\ UNIVERSITY OF SOUTHERN CALIFORNIA
}

\author{
STANFORD UNIVERSITY \\ UNIVERSITY OF TOKYO \\ UNIVERSITY OF UTAH \\ WASHINGTON STATE UNIVERSITY \\ UNIVERSITY OF WASHINGTON \\ AMERICAN MATHEMATICAL SOCIETY \\ CHEVRON RESEARCH CORPORATION \\ TRW SYSTEMS \\ NAVAL WEAPONS CENTER
}

Mathematical papers intended for publication in the Pacific Journal of Mathematics should be in typed form or offset-reproduced, double spaced with large margins. Underline Greek letters in red, German in green, and script in blue. The first paragraph or two must be capable of being used separately as a synopsis of the entire paper. It should not contain references to the bibliography. Manuscripts, in duplicate if possible, may be sent to any one of the four editors. All other communications to the editors should be addressed to the managing editor, Richard Arens, University of California, Los Angeles, California 90024.

Each author of each article receives 50 reprints free of charge; additional copies may be obtained at cost in multiples of 50 .

The Pacific Journal of Mathematics is published monthly. Effective with Volume 16 the price per volume (3 numbers) is $\$ 8.00$; single issues, $\$ 3.00$. Special price for current issues to individual faculty members of supporting institutions and to individual members of the American Mathematical Society: $\$ 4.00$ per volume; single issues $\$ 1.50$. Back numbers are available.

Subscriptions, orders for back numbers, and changes of address should be sent to Pacific Journal of Mathematics, 103 Highland Boulevard, Berkeley 8, California.

Printed at Kokusai Bunken Insatsusha (International Academic Printing Co., Ltd.), 7-17, Fujimi 2-chome, Chiyoda-ku, Tokyo, Japan.

PUBLISHED BY PACIFIC JOURNAL OF MATHEMATICS, A NON-PROFIT CORPORATION

The Supporting Institutions listed above contribute to the cost of publication of this Journal, but they are not owners of publishers and have no responsibility for its content or policies. 


\section{Pacific Journal of Mathematics}

\section{Vol. 26, No. $3 \quad$ BadMonth, 1968}

Leonard Asimow, Universally well-capped cones ................. 421

Lawrence Peter Belluce, William A. Kirk and Eugene Francis Steiner,

Normal structure in Banach spaces ..................... 433

William Jay Davis, Bases in Hilbert space.................... 441

Larry Lee Dornhoff, p-automorphic p-groups and homogeneous

algebras..................................... 447

William Grady Dotson, Jr. and W. R. Mann, A generalized corollary of the

Browder-Kirk fixed point theorem ....................... 455

John Brady Garnett, On a theorem of Mergelyan ................. 461

Matthew Gould, Multiplicity type and subalgebra structure in universal

algebras............................................. 469

Marvin D. Green, A locally convex topology on a preordered space . . . . . 487

Pierre A. Grillet and Mario Petrich, Ideal extensions of semigroups . . . . . . 493

Kyong Taik Hahn, A remark on integral functions of several complex

variables ... . . . . . . . . . . . . . . . . . . . . . . . . . . . . . . . . . . . 509

Choo Whan Kim, Uniform approximation of doubly stochastic

operators..................................... 515

Charles Alan McCarthy and L. Tzafriri, Projections in $\mathscr{L}_{1}$ and

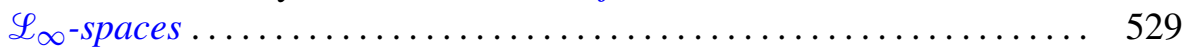

Alfred Berry Manaster, Full co-ordinals of RETs ................ 547

Donald Steven Passman, $p$-solvable doubly transitive permutation

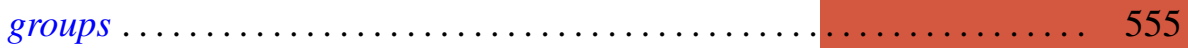

Neal Jules Rothman, An $L^{1}$ algebra for linearly quasi-ordered compact

semigroups ....................................... 579

James DeWitt Stein, Homomorphisms of semi-simple algebras .......... 589

Jacques Tits and Lucien Waelbroeck, The integration of a Lie algebra

representation ...............................

David Vere-Jones, Ergodic properties of nonnegative matrices. II ........ 601

Donald Rayl Wilken, The support of representing measures for $R(X) \ldots \ldots 621$

Abraham Zaks, Simple modules and hereditary rings .... . . 